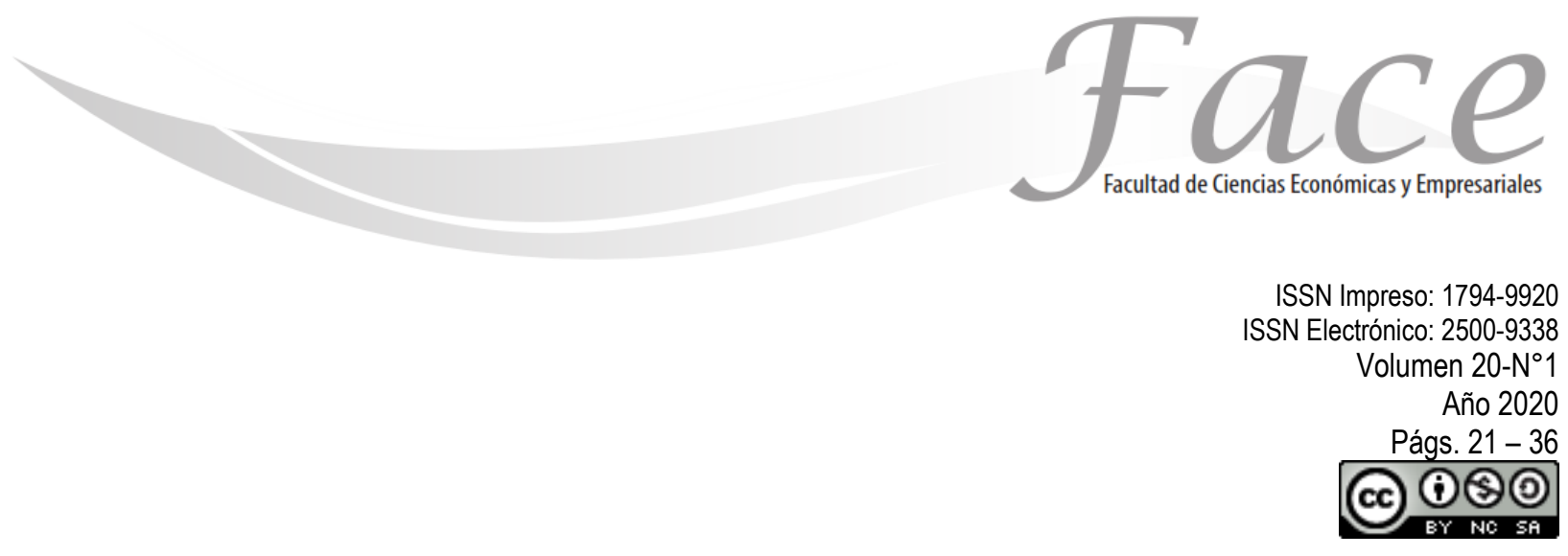

\title{
EVALUACION DEL CUMPLIMIENTO DE DEBERES FORMALES EN IMPUESTOS (I.S.L.R) E (I.V.A) EN THRONSON INTERNACIONAL DE VENEZUELA
}

\author{
Marianggeline Ch. Bracho Dúran* \\ https://orcid.org/0000-0001-9192-4660 \\ Andrés Cárdenas** \\ https://orcid.org/0000-0001-8552-8143 \\ Jeraldine Vergara*** \\ https://orcid.org/0000-0001-5629-9660
}

Fecha de Recepción: Marzo 20 de 2020

Fecha de Aprobación: Junio 19 de 2020

\section{Resumen:}

La investigación tuvo como objetivo evaluar el cumplimiento de los deberes formales en materia de Impuesto Sobre la Renta e Impuesto al Valor Agregado en la empresa Thronson Internacional de Venezuela, C.A. Referencia teórica: Caballenas (2004), Moya (2012), Ley del Impuesto Sobre la Renta (2015), Ley del Impuesto al Valor Agregado (2014), Código Orgánico Tributario (2014), entre otras. Metodología documental, diseño no experimental, tipo transversal. El instrumento el cuestionario de (49) ítems, respuestas dicotómica (si, no), evaluado por (3) expertos. Resultados evidenciaron que se cumple con lo establecido en las diferentes normas y leyes conforme al cumplimiento de los deberes formales. Se recomienda mantener actualizado al personal involucrado, en materia de impuesto sobre la renta e impuesto al valor agregado, para evitar sanciones logrando fortalecer el área tributaria.

Palabras clave: cumplimiento, deberes formales, impuesto, renta, valor agregado.

\footnotetext{
*Abogada - Contadora. Universidad Dr. Rafael Belloso Chacín. Maracaibo-Venezuela. Contacto: marianggeline@gmail.com.

** Contador. Universidad Dr. Rafael Belloso Chacín. Maracaibo-Venezuela. Contacto: andrescardenasw7@hotmail.com

${ }^{* * *}$ Contadora. Universidad Dr. Rafael Belloso Chacín. Maracaibo-Venezuela. Contacto: jeravergara67@gmail.com
} 


\title{
EVALUATION OF THE COMPLIANCE OF FORMAL DUTIES IN TAXES (I.S.L.R) AND (I.V.A) IN THRONSON INTERNATIONAL OF VENEZUELA
}

\begin{abstract}
:
The objective of the investigation was to evaluate the fulfillment of the formal duties regarding Income Tax and Value Added Tax in the company Thronson Internacional de Venezuela, C.A. Theoretical reference: Caballenas (2004), Moya (2012), Income Tax Law (2015), Value Added Tax Law (2014), Organic Tax Code (2014), among others. Documentary methodology, non-experimental design, transversal type. The instrument used the (49) item questionnaire, dichotomous responses (yes, no), evaluated by (3) experts. Results showed that the provisions of the different norms and laws are complied with in compliance with formal duties. It is recommended to keep the personnel involved updated on income tax and value added tax, in order to avoid sanctions, thereby strengthening the tax area.
\end{abstract}

Keywords: compliance, formal duties, tax, income, value added.

\section{AVALIAÇÃO DO CUMPRIMENTO DE DEVERES FORMAIS EM IMPOSTOS (I.S.L.R) E (I.V.A) EM THRONSON INTERNATIONAL DA VENEZUELA}

Resumo:

O objetivo da investigação foi avaliar o cumprimento dos deveres formais relativos ao imposto de renda e ao imposto sobre valor agregado na empresa Thronson Internacional de Venezuela, C.A. Referência teórica: Caballenas (2004), Moya (2012), Lei do Imposto de Renda (2015), Lei do Imposto sobre Valor Agregado (2014), Código do Imposto Orgânico (2014), entre outros. Metodologia documental, delineamento não experimental, tipo transversal. 0 instrumento utilizou o questionário (49) item, respostas dicotômicas (sim, não), avaliado por (3) especialistas. Os resultados mostraram que as disposições das diferentes normas e leis são cumpridas no cumprimento de obrigações formais. Recomenda-se manter o pessoal envolvido atualizado sobre imposto de renda e imposto sobre valor agregado, a fim de evitar sanções, fortalecendo a área tributária.

Palavras-chave: cumprimento, deveres formais, impostos, renda, valor agregado. 
Marianggeline Ch. Bracho Dúran - Andrés Cárdenas - Jeraldine Vergara

\section{INTRODUCCIÓN:}

Los tributos forman parte importante de la economía de un país, los cuales están contemplados en las diferentes leyes y normas establecidas en el Código Orgánico Tributario y cuya finalidad es contribuir a los gastos públicos para el logro de sus propios objetivos y cubrir con las necesidades de la sociedad. Por otra parte, según el marco jurídico de éstos, los tributos se clasifican en impuestos, tasas y contribuciones.

En relación a Venezuela, los tributos más relevantes que las empresas están obligadas a pagar en su posición de sujeto pasivo son el Impuesto Sobre la Renta y el Impuesto al Valor Agregado soportados en las diferentes regulaciones tributarias, como el Código Orgánico Tributario, la Ley del Impuesto Sobre la Renta y la Ley del Impuesto al Valor Agregado. Es por ello que, estas disposiciones legales forman parte de lo que es el Sistema Tributario Venezolano, que de esta manera se integra como mecanismo de control fiscal, entre la relación jurídica tributaria del sujeto activo (Estado) y el sujeto pasivo (Contribuyente).

Asimismo, se consideran los de mayor recaudación, y son monitoreados por el Servicio Nacional Integrado de Administración Aduanera y Tributaria (SENIAT), organismo que tiene el deber de dar un buen funcionamiento al Sistema Tributario de Venezuela, ya que posee la facultad de realizar la verificación y fiscalización otorgada por el Código Orgánico Tributario, es además quien ejerce el control sobre el cumplimiento de los deberes formales referido a las contribuciones 0 aportes establecidos por las distintas leyes y demás disposiciones de carácter tributario por parte de los sujetos pasivos del tributo.

De esta manera, Caballenas (2004, p.104), señala que el cumplimiento se encuentra relacionado con satisfacción de una obligación o deber.

Por otra parte, según el Glosario Tributario del SENIAT $(2015$, p.16) los deberes formales son las obligaciones que la Ley 0 las disposiciones reglamentarias, y aun las autoridades de aplicación de las normas fiscales, por delegación de la Ley, impongan a contribuyentes, responsables a terceros para colaborar con la Administración Aduanera y Tributaria en el desempeño de sus cometidos.

Visto así, puede decirse que el cumplimiento de los deberes formales implica la satisfacción de una obligación o deber, que las autoridades de aplicación de las normas fiscales, por delegación de la Ley, impongan a contribuyentes, responsables a terceros para colaborar con la Administración Tributaria y aduanera en el desempeño de sus cometidos. (Caballenas, 2004, p.104; SENIAT, 2015, p. 16).

Sobre las bases de las ideas expuestas, se presenta a la empresa Thronson Internacional de Venezuela, C.A., cuya misión radica en ser una empresa dedicada a proveer servicios de ingeniería, procura y gerencia de construcción, para satisfacer los requerimientos de calidad dentro de los costos y tiempos establecidos, logrando un rendimiento económico que permita satisfacer las expectativas de sus accionistas y el bienestar de sus trabajadores.

A través de una entrevista realizada al contador de Thronson Internacional de Venezuela, C.A., éste manifestó que existen incertidumbre por parte de la gerencia de la empresa en lo que se refiere al cumplimiento de los deberes formales relacionados con el Impuesto Sobre la Renta y el Impuesto al Valor Agregado, motivado a que la misma hasta los momentos no ha sido fiscalizada.

En función de lo planteado frente a una posible fiscalización por parte de la Administración Tributaria de conformidad con lo establecido en el Código Orgánico Tributario, la empresa pudiese ser sancionada,

Partiendo de los planteamientos anteriores, se realiza una evaluación del cumplimiento de los deberes formales en materia de Impuesto Sobre la Renta e Impuesto al Valor Agregado en la empresa Thronson Internacional de Venezuela, C.A., con el fin de suministrar información oportuna y confiable a la gerencia, sobre las debilidades que se pudiesen estar presentando en el cumplimiento de los deberes formales en materia de Impuesto Sobre la Renta e Impuesto al Valor Agregado y así aplicar los correctivos necesarios a que hubiere lugar, evitando que ante una fiscalización por parte del Seniat esta pueda ser sancionada según lo establecido en el Código Orgánico Tributario.

En tal sentido, toda actividad económica trae consigo el cumplimiento de los deberes formales, considerados como obligaciones que deben cumplir los sujetos pasivos, establecidas en diferentes normas mediante leyes, reglamentos y providencias las cuales permiten regular el modo en el que las empresas llevan a cabo sus actividades en el ámbito tributario.

Por tal razón, la presente investigación se realizó partiendo de la inquietud de los investigadores en la evaluación de los deberes formales tributarios en materia de Impuesto Sobre la Renta e Impuesto al 
Valor Agregado en la empresa Thronson Internacional de Venezuela, C.A., al respecto, se justificaría desde el punto de vista teórico, práctico y metodológico. También se tuvo como referencia el trabajo realizado por Berrio, Pérez, y Brito (2017), donde la gestión financiera como eje fundamental para toma decisiones donde la arista tributaria es de carácter fundamental.

En este sentido, desde el punto de vista teórico, se analizó e interpretó la información importante sobre el cumplimiento de los deberes formales del Impuesto Sobre la Renta e Impuesto al Valor Agregado, tomando en cuenta la variable por medio de diferentes aportes de autores, que serviría de apoyo para ampliar todo lo relacionado a la variable en estudio, ya que esta información podrá ser usada como fuente de consulta para investigaciones futuras.

Desde la perspectiva práctica, esta investigación proporcionó información a la gerencia de Thronson Internacional de Venezuela C.A., sobre las debilidades que se pudiesen estar presentando en el cumplimiento de los deberes formales en materia de Impuesto Sobre la Renta e Impuesto al Valor Agregado y así aplicar los correctivos necesarios a que hubiere lugar, evitando que ante una fiscalización por parte del SENIAT esta pueda ser sancionada según lo establecido en el Código Orgánico Tributario.

\section{MARCO TEORICO:}

\section{Tributos}

Los tributos son las prestaciones en dinero que el estado en el ejercicio de su poder de imperio exige mediante de una ley, para cubrir los gastos que le demanda el cumplimiento de sus fines. De esta manera, Moya $(2012$, p.217) se refiere a los tributos como las prestaciones exigidas en dinero que el Estado u otro ente público exige en el ejercicio de su poder de imperio en virtud de una ley con el fin de obtener recursos para financiar los gastos que le demanda el cumplimiento de sus fines. El tributo también definido al cumplimento como obligación en organizaciones modernas como lo plantea en su trabajo Moncada (2016).

\section{Cumplimiento}

Cumplimiento Fiscal ha sido definido por la Organización para la Cooperación y el Desarrollo Económico (OCDE) (2015, p. 13) como las disposiciones legales y reglamentarias que deben cumplirse de carácter fiscal de todos los países en los que ejercen su actividad fiscal y deberán hacer cuanto esté a su alcance para actuar de conformidad con la letra y el espíritu de dichas disposiciones legales y reglamentarias.

Así mismo señalan Beltrán, J., \& González, L. (2017)., como la contabilidad funciona de coadyuvante del cumplimiento de las responsabilidades de los contribuyentes, sistematizando las políticas tributarias dependiendo de la estructura del sistema impositivo, distribución social, efectos de los tributos y su utilización como instrumentos dinámicos necesario para el subsistema económico.

\section{Deberes Formales Tributarios}

Son aquellas obligaciones formales que corresponden a los contribuyentes, por la administración de acuerdo al mandato de la Ley tributaria que rigen materia en el país. Landwell (2010, p. 142) describe los deberes formales como prestaciones obligatorias por hacer, deberes jurídicospolíticos, impuestos por una entidad pública en ejercicio de potestades tributarias.

\section{Impuesto Sobre la Renta}

El impuesto Sobre la Renta es una imposición directa sobre los aquellos aumentos que son generados del capital que ha sido invertido, tanto dentro como fuera del territorio nacional. Al respecto, Garay y Garay (2012, p. 75), manifiesta que es un impuesto encargado de gravar las rentas disponibles y netas, obtenidas en dinero o especie provenientes de bienes que se encuentren en Venezuela 0 de actividades realizadas en el exterior.

Del mismo modo expresan Pájaro y Ramos (2015), como deben considerarse las variables internas y micro económicas con conexión a la liquidez y rentabilidad ya que están directamente relacionadas con la capitalización de las empresas. Las rentas fijas $y$ variables deben ser analizadas como instrumentos directos que miden el rendimiento de alternativas. 
Marianggeline Ch. Bracho Dúran - Andrés Cárdenas - Jeraldine Vergara

\section{Deberes Formales del ISLR}

\section{Declaración Estimada}

Para dar comienzo a los deberes formales que encierra el Impuesto Sobre la Renta, conviene precisar en primer orden la obligación de realizar una declaración estimada, la cual según el Glosario Aduanero Tributario emitido por el SENIAT (2015) es un deber formal establecido en la Ley para determinadas categorías de sujetos pasivos, obteniendo de éstos el pago del tributo en forma anticipada, la cual debe presentarse a través de los medios autorizados por la Administración Aduanera y Tributaria y en los lapsos establecidos en la Ley.

\section{Declaración Anual Definitiva}

Existe, en cuanto declaración se trata, otra modalidad denominada declaración definitiva, la cual se encuentra conceptualizada por el Glosario Aduanero Tributario emitido por el SENIAT (2015) como el deber formal del sujeto pasivo de presentar en los formularios oficiales emitidos por la Administración Aduanera y Tributaria o por vía electrónica, los resultados fiscales de un ejercicio o período de imposición.

\section{Declaración Informativa}

Dentro de la serie de declaraciones del impuesto sobre la renta que impone la ley, también se encuentra la declaración informativa, definida por el Glosario Aduanero Tributario emitido por el SENIAT (2015) como aquella declaración jurada realizada por el sujeto pasivo en la que se suministra información o datos, necesarios para el ejercicio del control fiscal y cuya presentación constituye un deber formal.

Siendo así, va dirigida a las personas naturales 0 jurídicas que directamente realicen una serie de actividades de inversiones en territorios donde la imposición fiscal es baja, debiendo presentar en nuestro país una relación de las nombradas inversiones realizadas, dentro de la fecha del cierre del ejercicio indicado para la declaración definitiva, de forma detallada con sus respectivos soportes.

\section{Ajuste por Inflación}

Según Moya (2012, p. 270) el ajuste inicial por inflación tiene como finalidad favorecer imparcialmente el gravamen al fenómeno inflacionario de manera que no recaiga sobre ganancias nominales pero irreales. Es la realización a los efectos tributarios de la actualización extraordinaria de los activos y pasivos no monetarios, el cual servirá como referencia al sistema de ajuste por inflación y traerá como consecuencia una variación en el monto del patrimonio neto para la fecha de la realización de dicho ajuste.

\section{Comprobantes de Retención de ISLR}

Dentro de la gama de los deberes formales correspondientes al Impuesto sobre la Renta, se encuentra el deber de emitir los comprobantes de retención, siendo definidos estos por el Glosario Aduanero Tributario emitido por el SENIAT (2015) como un documento de emisión obligatoria por parte de los agentes de retención a los contribuyentes, en el que se indica el monto de las retenciones practicadas, conforme a las disposiciones legales vigentes.

Constituyendo así un deber sine qua non, por parte de los agentes de retención, debiendo mostrar en ellos la suma de lo pagado y el total retenido, debiendo ser anexado estos comprobantes la declaración definitiva del Impuesto, en las formas, plazos y condiciones que la Administración Tributaria establezca.

\section{Pagos}

Al margen del Impuesto Sobre la Renta como institución tributaria es pertinente la definición del Glosario Aduanero Tributario emitido por el SENIAT (2015) la cual infiere que el pago es uno de los medios que permite al sujeto pasivo extinguir de la obligación tributaria, representado en la entrega de un dinero que se adeuda al Estado, el cual debe efectuarse en el lugar, fecha y forma que indique la ley tributaria o su reglamentación.

Adicionalmente, el artículo 85 de la Ley del Impuesto Sobre la Renta (2015) aduce que los contribuyentes deberán determinar sus enriquecimientos, calcular los impuestos correspondientes y proceder a su pago de una sola vez ante las Oficinas Receptoras de Fondos Nacionales, en la forma y oportunidad que establezca el Reglamento.

\section{Impuesto al Valor Agregado}

IVA es un impuesto nacional a los consumos que tiene que ser abonado por las personas naturales 0 jurídicas en cada una de las etapas del proceso económico. De acuerdo con Ruiz, (2011, p. 24) 
determina el impuesto al valor agregado "como un tributo que se paga en todas las etapas de producción y distribución sin tener un efecto acumulativo pues el objeto de la imposición no representa el valor total de bien sino el mayor valor que el producto adquiere".

\section{Deberes Formales del IVA}

Los deberes formales son obligaciones impuestas por el código orgánico tributario 0 por otras normas tributarias a los contribuyentes, responsables 0 determinados terceros (Ruiz, 2011, p. 13). Según el glosario aduanero y tributario los deberes formales constituyen las obligaciones que la ley 0 las disposiciones reglamentarias, y aun las autoridades de aplicación de las normas fiscales, por delegación de la ley, impongan a contribuyentes, responsables 0 terceros.

\section{Declaración Mensual}

La En la Ley del Impuesto al Valor Agregado (2014, p. 47) en su artículo 47 establece que las declaraciones es la obligación de los adquirientes de bienes 0 receptores de servicios, así como de entes del sector público, de exigir al sujeto pasivo las declaraciones de periodos anteriores para tramitar el pago correspondiente.

El reglamento de la ley que establece el impuesto al valor agregado (1999, p. 12) en su artículo 59 establece lo siguiente: Los contribuyentes y responsables deberán presentar declaración jurada por las operaciones gravadas y exentas, realizadas en cada período mensual de imposición. En dicha declaración dejarán constancia de la suma de los débitos fiscales que consten en las facturas emitidas en el período de imposición, así como de las sumas de los impuestos soportados y que le han sido trasladados como créditos fiscales en las facturas recibidas en el mismo período; con inclusión de las notas de débito y crédito correspondientes.

\section{Comprobantes de Retención de IVA}

Según la providencia $0049(2015$, p. 7$)$ en su artículo 16, "los agentes de retención están obligados a entregar a los proveedores un comprobante de cada retención de impuesto que les practiquen, el mismo debe emitirse y entregarse al proveedor a más tardar dentro de los primeros dos (2) días hábiles del periodo de imposición siguiente del Impuesto al Valor Agregado.

\section{Pagos}

El reglamento de la ley del impuesto al valor agregado (1999, p. 13) en su artículo 60 establece lo siguiente: La determinación y pago del impuesto se deberá efectuar en el formulario de declaración y pago, medios y sistemas autorizados por el Ministerio de Hacienda, y presentarse dentro de los quince (15) días continuos siguientes al período de imposición, ante las instituciones bancarias que hayan celebrado convenios con la Administración Tributaria u otras oficinas autorizadas.

Los contribuyentes y los responsables en su caso, que posean más de un establecimiento en que realicen sus operaciones 0 que desarrollen actividades gravadas diversas, deberán presentar una sola declaración, en los términos antes previstos, en la jurisdicción del domicilio fiscal de la casa matriz del contribuyente.

\section{METODOLOGÍA:}

\section{Tipo de Investigación}

La investigación es de tipo documental, descriptiva, debido a que su propósito se enfoca en la verificación del cumplimiento de los deberes formales que debe acatar a cabalidad la empresa Thronson Internacional de Venezuela C.A, netamente comprobables con las respectivas declaraciones, facturas y libros, de conformidad con lo estipulado en la legislación tributaria venezolana. Por su parte Arias (2012, p. 49) manifiesta ser una investigación documental "aquella que se basa en la obtención y análisis de datos provenientes de materiales impresos $u$ otros tipos de documentos".

Asimismo es considera descriptiva, debido al análisis enmarcado en el cumplimiento de los deberes formales relacionados con los impuestos antes mencionados, dentro de la organización, especificando claramente los documentos objetos de estudio. Asevera Tamayo y Tamayo (2017), que la investigación demuestra la realidad de los hechos, especificando e interpretándolos de forma acertada, y comparando evidencias. 


\section{Diseño de la Investigación}

Esta investigación tiene un diseño no experimental, transaccional, los fenómenos objeto de estudio, se desarrollan en la realidad, bajo un imperativo legal, no permitiendo así la manipulación de las variables. Palella y Martins (2017; p.87) definen una investigación no experimental como "aquella que se realiza sin manipular en forma deliberada ninguna variable".

Por su parte, Hernández, Fernández y Baptista (2014, p. 208) indican estar en presencia de una investigación transaccional cuando "se obtienen los datos sobre el fenómeno en una sola oportunidad, y esto se debe a que la recolección de datos se realizara en un único momento". Así mismo, es transaccional debido al desarrollo único que tiene, se da el estudio en un momento específico, con el traslado de los investigadores a la empresa para la revisión de los documentos

Cuadro 1

Distribución de la Población concuerden con determinadas especificaciones". Mientras que de acuerdo a Tamayo y Tamayo (2017, p. 176) "la población se define como la totalidad del fenómeno a estudiar donde las unidades de población poseen una característica común la cual se estudia y da origen a los datos de la investigación"

En esta investigación se tomó de población los documentos que permiten evidenciar el cumplimiento delos deberes formales en materia de Impuesto sobre la renta ISRL e impuesto al valor agregado IVA en la empresa Thronson Internacional de Venezuela C.A, conformados por diferentes, libros, facturas $y$ declaraciones, todo de acuerdo a lo estipulado por la normativa legal. La presente población es manejable, considerándose así el criterio de censo poblacional por Tamayo y Tamayo (2017, p. 109), quien plantea que la totalidad es la muestra más representativa por ser finita y accesible.

\begin{tabular}{c|l}
\hline \multicolumn{1}{c|}{ EMPRESA } & \multicolumn{1}{c}{ DOCUMENTOS } \\
\hline \multirow{2}{*}{ Thronson Internacional de Venezuela. C.A. } & Declaración estimada del ISRL \\
\cline { 2 - 2 } & Declaración definitiva del ISRL \\
\cline { 2 - 2 } & Declaración informativa del ISLR \\
\cline { 2 - 2 } & Comprobantes de retención del ISRL \\
\cline { 2 - 2 } & Libros fiscales \\
\cline { 2 - 2 } & Libros contables \\
\cline { 2 - 2 } & Registro de información fiscal \\
\cline { 2 - 2 } & Libro de Compra \\
\cline { 2 - 2 } & Libro de ventas \\
\cline { 2 - 2 } & Declaración mensual del IVA \\
\cline { 2 - 2 } & Facturas \\
\cline { 2 - 2 } & Comprobantes de retención del IVA \\
\cline { 2 - 2 } & Comprobantes de pago IVA. \\
\hline
\end{tabular}

Fuente: Thronson Internacional de Venezuela C.A. (2019)

La población es definida por Hernández y otros (2014, p.304), como "el conjunto de todos los casos que 
La técnica utilizada en este estudio fue la observación directa documental mediante tabla estructurada de preguntas, ya que se realizó a través del análisis de los documentos presentes, para la respectiva comprobación del cumplimiento de los deberes formales objeto de estudio. Tamayo y Tamayo (2017, p. 193), define la observación directa como "aquella en la cual el investigador puede observar y recoger datos mediante su propia observación".

En este caso, para el desarrollo de esta investigación se utilizó una guía de observación documental, la cual será aplicada observando los documentos de la Empresa Thronson Internacional de Venezuela, C.A. La misma está compuesta por 49 ítems para evaluar 16 unidades de análisis con peguntas alternativas $\mathrm{SI}$, NO y N/A. Asi mismo, Palella y Martins (2017; p 125) indica ser cualquier recurso del que pueda valerse el investigador para acercarse a los fenómenos y extraer de ellos información.

\section{RESULTADOS:}

El análisis que se muestra a continuación, se realizó interpretando cada una de las respuestas obtenidas en el instrumento aplicando en forma de cuestionario, el cual estuvo conformado por cuarenta y nueve (49) preguntas con opciones de respuestas SI, NO Y N/A, aplicados a los documentos de la gerencia de finanzas de la empresa Thronson Internacional de Venezuela C.A. Posterior a la recolección de la información, se procedió a detallarlas en las tablas, con respecto a cada alternativa de respuestas y frecuencia. A continuación se muestran los resultados:

Variable: Cumplimiento de los deberes formales.

Categoría: Cumplimiento de la normativa legal que regula los deberes formales en materia de Impuesto Sobre la Renta

Unidad de análisis: Realizar el registro como contribuyente del ISLR.
Tabla 1

Registro de Información Fiscal

\begin{tabular}{|c|c|c|}
\hline \multirow[t]{2}{*}{ Inscripción Fiscal } & \multicolumn{2}{|c|}{ Alternativas } \\
\hline & $\mathrm{SI}$ & NO \\
\hline $\begin{array}{l}\text { Posee registro de información } \\
\text { fiscal. }\end{array}$ & 1 & 0 \\
\hline Se exhibe en un lugar visible. & 1 & 0 \\
\hline Razón social de contribuyente. & 1 & 0 \\
\hline $\begin{array}{l}\text { Clase o tipo de sociedad } 0 \\
\text { entidad. }\end{array}$ & 1 & 0 \\
\hline Fecha de inscripción. & 1 & 0 \\
\hline Domicilio Fiscal. & 1 & 0 \\
\hline $\begin{array}{l}\text { Dirección de la sede } \\
\text { administrativa. }\end{array}$ & 1 & 0 \\
\hline
\end{tabular}

De acuerdo a las observaciones en la tabla 1, la entidad posee el registro de información fiscal lo cual es exhibido en un lugar visible y se contempla la razón social, la clase o tipo de sociedad, fecha de inscripción ante la administración tributaria, domicilio fiscal y dirección de la sede administrativa.

Unidad de análisis: Presentar la declaración estimada del ISLR.

Tabla 2

Declaración Estimada del ISLR

Declaración Alternativas

Obtuvo dentro del año inmediatamente anterior enriquecimiento netos superior $\begin{array}{ll}0 & 1\end{array}$ a 1500 U.T.

Considero los datos de la declaración definitiva del ejercicio anterior para la $0 \quad \mathrm{~N} / \mathrm{A}$ elaboración de la estimada.

Calculo la declaración estimada en base al $80 \%$ de la utilidad contable correspondiente al año inmediato $0 \quad N / A$ anterior.

Fuente: Bracho, Cárdenas, Vergara (2019) 
Marianggeline Ch. Bracho Dúran - Andrés Cárdenas - Jeraldine Vergara

Unidad de análisis: Presentar la declaración anual definitiva del ISLR.

Tabla 3

Declaración Anual del ISLR

\begin{tabular}{lll}
\hline Declaración & \multicolumn{2}{l}{ Alternativas } \\
\hline $\begin{array}{l}\text { Presenta la declaración anual definitiva } \\
\text { con los resultados fiscales del periodo }\end{array}$ & 1 & NO \\
de imposición. & & \\
$\begin{array}{l}\text { Presenta la declaración anual de sus } \\
\text { enriquecimientos, tanto como pérdidas. }\end{array}$ & 1 & 0 \\
$\begin{array}{l}\text { Ha utilizado alguna prórroga para la } \\
\text { presentación. }\end{array}$ & 0 & 1
\end{tabular}

Fuente: Bracho, Cárdenas, Vergara (2019)

Con referencia a la tabla 3 , se observa que efectivamente se presentó la declaración anual definitiva del ISLR con los resultados fiscales del periodo de imposición tanto de sus enriquecimientos como de sus pérdidas, declarando dentro de los tres (3) meses siguientes al cierre del ejercicio gravable por lo cual no han utilizado alguna prórroga para la presentación.

Unidad de análisis: Efectuar el ajuste por inflación para

la determinación de la renta neta.
De acuerdo con las respuestas dadas a las alternativas presentadas, la empresa no realiza ajuste por inflación desde el año 2015 debido a una reforma legal emitida por el Gobierno Nacional en materia de ajuste inflacionario en Diciembre del año mencionado, la cual por la naturaleza de la organización se adapta a lo establecido.

Unidad de análisis: Llevar los libros y los registros contables.

Tabla 5

Llevar los libros y registros contables del ISLR

\begin{tabular}{ll}
\hline Libro diario & Alternativas \\
\hline & SI \\
La empresa lleva de forma ordenada tanto los & 1 \\
libros como los registros contables. & \\
Lleva de forma ajustada a los principios de & \\
contabilidad generalmente aceptados tanto & 1 \\
los libros como los registros. & \\
Son elaborados de acuerdo a los principios de & \\
contabilidad generalmente aceptados tanto \\
en el balance general como el estado de \\
resultado.
\end{tabular}

La empresa cumple a cabalidad el deber formal respecto a los libros de contabilidad con los adecuados registros, de acuerdo a lo principios generalmente aceptados y de forma perfectamente ordenada.

Tabla 4

Ajuste por Inflación

\begin{tabular}{lll}
\hline Declaración & Alternativas & \\
\hline & SI & NO \\
$\begin{array}{l}\text { Realizó el ajuste inicial integral por } \\
\text { inflación en base a sus activos y pasivos }\end{array}$ & 0 \\
no monetarios. & \\
$\begin{array}{l}\text { Realizó el ajuste al cierre de su primer } \\
\text { ejercicio gravable. }\end{array}$ & N/A & N/A \\
$\begin{array}{l}\text { Se realizó el ajuste por inflación utilizando } \\
\text { la variación del Índice Nacional de Precios } \\
\text { al Consumidor (INPC). }\end{array}$ & N/A \\
\hline $\begin{array}{l}\text { Fuente: Bracho, Cárdenas, Vergara (2019) } \\
\end{array}$ & \\
\hline
\end{tabular}

Tabla 6

Emitir los comprobantes de retención del ISLR

\begin{tabular}{lcc}
\hline Comprobantes de Retención de ISLR & Alternativas & \\
\hline $\begin{array}{l}\text { Como agente de retención emite los } \\
\text { debidos comprobantes. }\end{array}$ & 1 & SI \\
$\begin{array}{l}\text { Los comprobantes contienen } \\
\text { información sobre el monto de lo }\end{array}$ & 1 & 0 \\
pagado o abonado en cuenta y la \\
cantidad retenida.
\end{tabular}


Los comprobantes de retención son emitidos por la organización, en los tiempos y formas correctas establecidas, demostrando así al trabajador el monto abonado o retenido.

Unidad de análisis: Declarar y pagar el impuesto correspondiente según la fecha, forma y condición que establezca el reglamento.

Tabla 7

Declarar y pagar el impuesto correspondiente según la fecha, forma y condición que establezca el reglamento del ISLR

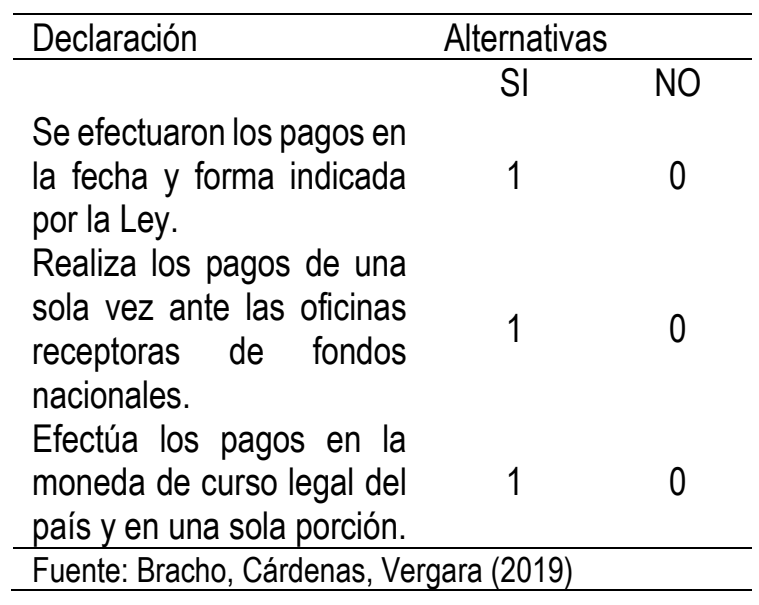

Se evidencio el cumplimiento de la declaración y pago del impuesto sobre la renta, todo bajo las normas imperativas que establece el reglamento de la ley, según los lapsos pertinentes y las formas indicadas.

Categoría: Cumplimiento de la normativa legal que regula los deberes formales en materia de Impuesto al Valor Agregado.

Unidad de análisis: Realizar el registro como contribuyente del IVA.
Tabla 8

Registro como contribuyente del IVA

\begin{tabular}{|c|c|c|}
\hline Inscripción Fiscal & Alte & \\
\hline & SI & NO \\
\hline $\begin{array}{l}\text { Se encuentra inscrito ante la } \\
\text { Administración Tributaria. } \\
\text { La inscripción del registro de } \\
\text { contribuyente contiene. }\end{array}$ & 1 & 0 \\
\hline Lugar de registro. & 1 & 0 \\
\hline Formalidades. & 1 & 0 \\
\hline Condiciones. & 1 & 0 \\
\hline Requisitos e información. & 1 & 0 \\
\hline $\begin{array}{ll}\text { Posee más de un } \\
\text { establecimiento en el que } \\
\text { realicen } & \text { operaciones } \\
\text { gravadas. } & \end{array}$ & 1 & 0 \\
\hline
\end{tabular}
Fuente: Bracho, Cárdenas, Vergara (2019)

De acuerdo a la tabla 8, Thronson Internacional de Venezuela C.A., efectivamente se encuentra inscrita ante la Administración Tributaria. Así mismo, la empresa exhibe el comprobante de inscripción en un lugar visible el cual contiene lugar de registro, formalidades, condiciones y requisitos e información fiscal, así como también posee más de un establecimiento en el que se realizan operaciones gravadas.

Unidad de análisis: Emisión de facturas y otros documentos por operaciones gravadas.

Tabla 9

Emisión de Facturas y otros Documentos

\begin{tabular}{|c|c|c|}
\hline Facturas y otros documentos & & \\
\hline & $\mathrm{SI}$ & $\mathrm{NO}$ \\
\hline $\begin{array}{l}\text { Cumple con la obligación de emitir } \\
\text { facturas por las ventas realizadas y } \\
\text { otras operaciones gravadas. }\end{array}$ & 1 & 0 \\
\hline $\begin{array}{l}\text { Se cumple con la obligación de emitir } \\
\text { documentos. }\end{array}$ & 1 & 0 \\
\hline $\begin{array}{l}\text { Se emite la factura por duplicado. } \\
\text { Las facturas se presentan como se } \\
\text { mencionan a continuación. }\end{array}$ & 1 & 0 \\
\hline Presenta numeración consecutiva. & 1 & 0 \\
\hline $\begin{array}{l}\text { Presenta número de control y } \\
\text { Número de RIF. }\end{array}$ & 1 & 0 \\
\hline $\begin{array}{l}\text { Presenta nombre completo y } \\
\text { domicilio fiscal del emisor. }\end{array}$ & 1 & 0 \\
\hline $\begin{array}{l}\text { Presenta especificación del monto } \\
\text { del impuesto según alícuota. }\end{array}$ & 1 & 0 \\
\hline
\end{tabular}


Unidad de análisis: Presentar la declaración del IVA

Al evidenciar en la tabla 9, la empresa cumple con la obligación de emitir facturas y documentos por las ventas realizadas y por las demás operaciones gravadas, además de emitirlas por duplicado. Por otra parte, las facturas se presentan con la numeración consecutiva, con su número de control y numero de Rif, nombre completo y domicilio fiscal del emisor, así como la especificación del monto del impuesto según la alícuota.

Unidad de análisis: Llevar libros de compra y venta al día y archivados.

Tabla 10:

Libros de compra y venta al día y archivados

Libros de compra y venta

Presenta el contribuyente los libros de compras y ventas.

Registran de forma cronológicas todas las operaciones que se realizan.

Llevan estos libros la información relativa a sus operaciones internas.

Importaciones documentadas

mediante facturas.

Exportaciones documentadas

mediante facturas.

Notas de Débitos y Créditos.

Fuente: Bracho, Cárdenas, Vergara (2019)

Alternativas

SI NO

10

10

Las respuestas obtenidas en la tabla 11, con respecto

Como se puede evidenciar en la tabla 10, Thronson Internacional de Venezuela C.A., efectivamente contiene los libros de compras y ventas correspondientes, además de que se encuentran los registros en orden cronológicos según las operaciones que se han realizado. Así mismo, estos libros llevan las informaciones relativas a las importaciones $y$ exportaciones documentadas mediante facturas, como notas de débitos y créditos. a la declaración mensual del I.V.A en la empresa pagan el impuesto correspondiente en el lugar fecha, forma y condición que establezca el reglamento. Así mismo, presenta la declaración dentro de los quince (15) días continuos siguientes al periodo de imposición.

Unidad de análisis: Realizar los registros contables del IVA.

mensual.

Tabla 11

Declaración mensual del IVA

\begin{tabular}{lcc}
\hline Declaración & Alternativas & \\
\hline $\begin{array}{l}\text { Presenta la declaración del } \\
\text { impuesto. }\end{array}$ & 1 & SI \\
Presenta la declaración jurada & & \\
por las operaciones gravadas \\
realizadas en el periodo \\
mensual de imposición.
\end{tabular}

Tabla 12

Registros Contables del IVA

Registros Contables

Alternativas

Registra contablemente todas sus

operaciones, incluyendo las que no $1 \quad 0$

son gravables con el IVA.

Registra contablemente las nuevas

facturas, documentos equivalentes a

nota de débitos y créditos emitidas y

$1 \quad 0$

recibidas.

Fuente: Bracho, Cárdenas, Vergara (2019) 
Según la tabla 12, la empresa efectivamente registra contablemente todas sus operaciones, incluyendo las que no son gravables con el I.V.A, además registra las nuevas facturas 0 documentos equivalentes, las notas de débitos y créditos emitidas o recibidas.

Unidad de análisis: Llevar libros, registros archivos adicionales

Tabla 13 Unidad de análisis: Llevar libros, registros archivos adicionales Libros, registros y archivos adicionales

\begin{tabular}{lll}
\hline Libros Fiscales & Alternativas \\
\hline $\begin{array}{l}\text { Lleva los libros, registros y archivos } \\
\text { adicionales necesarios }\end{array}$ & 1 & NO \\
$\begin{array}{l}\text { Conservan en forma ordenada las facturas } \\
\text { utilizadas para la elaboración de asientos y }\end{array}$ & 1 & 0 \\
registros correspondientes. \\
$\begin{array}{l}\text { Conservan en forma ordenada los libros, } \\
\text { mientras no esté prescrita la obligación. }\end{array}$
\end{tabular}

Fuente: Bracho, Cárdenas, Vergara (2019)

Para la tabla 13, en la empresa Thronson Internacional de Venezuela, C.A, se observa que llevan al día los libros, registros y archivos adicionales necesarios tales como libro diario fiscal, libro mayor fiscal, balance general fiscal, conservando en forma ordenada mientras no esté prescrita la obligación las facturas utilizadas para la elaboración de dichos libros.

Unidad de análisis: Emitir los comprobantes de retención de IVA.

\section{Tabla 14}

Emisión de comprobantes de retención de IVA

\begin{tabular}{lll}
\hline Comprobantes de retención de IVA & Alternativas & \\
\hline $\begin{array}{l}\text { Presenta un oficio designado y calificado } \\
\text { como responsable del pago del impuesto }\end{array}$ & 1 & NO \\
emitido por el SENIAT. & 0 \\
$\begin{array}{l}\text { Contiene el comprobante de retención la } \\
\text { razón social del agente de retención. }\end{array}$ & 1 & 0 \\
$\begin{array}{l}\text { Contiene el comprobante de retención la } \\
\text { fecha de emisión del comprobante. }\end{array}$ & 1 & 0 \\
$\begin{array}{l}\text { Se entrega el comprobante de retención a } \\
\text { cada proveedor por cada retención de } \\
\text { impuesto que se les practique. }\end{array}$ & 1 & 0 \\
\hline
\end{tabular}

Fuente: Bracho, Cárdenas, Vergara (2019)
De acuerdo a la tabla 14, la empresa presenta un oficio designado y calificado responsable del pago del impuesto emitido por la administración tributaria, de igual forma cumple con entregar a los proveedores los comprobantes por cada retención de IVA que se les practiquen, detallando en estos la razón social del agente de retención, la fecha de emisión y el importe calculado.

Unidad de análisis: Declara y pagar el impuesto correspondiente según la fecha, forma y condición que establezca el reglamento.

Tabla 15

Declarar y pagar el impuesto correspondiente según lo establezca el reglamento

Declaraciones y planillas de pago Alternativas

Cumple con la declaración y pago de los anticipos de IVA de acuerdo a las normas 1 de la administración tributaria.

Cancela el impuesto por las importaciones definitivas, que serán determinadas y pagadas en el momento en que ya haya SI NO nacido la obligación tributaria.

Fuente: Bracho, Cárdenas, Vergara (2019)

Por último, la tabla 16, señala que la organización cumple con la obligación de declarar y pagar el impuesto al valor agregado según fecha, forma y condición establecida por reglamento, cancelando el impuesto por las importaciones definitivas, así como también declara y paga los anticipos de IVA generados inmediatamente de la declaración de IVA.

\section{DISCUSIÓN DE RESULTADOS:}

Los resultados de la presente investigación están orientados a responder el objetivo general planteado que consistió en evaluar el cumplimiento de los deberes formales en materia de Impuesto Sobre la Renta (ISLR) e Impuesto al Valor Agregado (IVA) en la empresa Thronson Internacional de Venezuela, C.A.

Referente al cumplimiento de la normativa legal que regula los deberes observaciones formales en materia de Impuesto Sobre la Renta, las realizadas muestra que el registro de información fiscal está elaborado apegado al deber formal de inscribirse en los registros pertinentes según lo dispuesto en el artículo 180 del 
Marianggeline Ch. Bracho Dúran - Andrés Cárdenas - Jeraldine Vergara

Reglamento de la Ley de Impuesto Sobre la Renta (2003).

De la misma forma se evidenció que la empresa no realizó la declaración estimada por no haber obtenido enriquecimientos netos superiores a mil quinientas unidades tributarias (1500 U.T), del año inmediatamente anterior al ejercicio en curso, atendiendo a lo establecido en el artículo 80 de la Ley de Impuesto Sobre la Renta (2015).

Con respecto a la declaración anual definitiva, la entidad se apega al artículo 140 del Reglamento del Impuesto Sobre la Renta (2003), conteniendo todos los enriquecimientos o pérdidas dentro y fuera del territorio venezolano.

Por su parte, la empresa realizó el ajuste inicial por inflación de sus activos y pasivos no monetarios, cumpliendo así con el artículo 171 de la Ley de Impuesto Sobre la Renta (2015), sin embargo no realiza el reajuste regular por inflación desde el año 2015 debido a una reforma tributaria emitida por el Gobierno Nacional en dicho año.

Así mismo, en relación a los libros y registros contables la organización cumple a cabalidad con el artículo 88 de la Ley de Impuesto Sobre la Renta (2015), donde indica que deben ser llevados en forma ordenada de manera que constituyan medios integrados de control y comprobación para ser exhibidos ante funcionarios fiscales competentes, así como también cumple con lo dicho en el artículo 145 del Código Orgánico Tributario (2014), que tanto los libros como los registros especiales deberán ser llevados conforme a los principios de contabilidad generalmente aceptados.

En cuanto, a la emisión de los comprobantes de retención la empresa cumple con la entregada a los contribuyentes por cada retención de impuesto practicada indicando el monto de lo pagado o abonado en cuenta y la cantidad retenida, atendiendo el artículo 24 del decreto 1.808, Reglamento de la Ley de Impuesto Sobre la Renta (1997).

Por otra parte la declaración y pago del impuesto sobre la renta, la empresa opta por presentar las declaraciones a través de medios electrónicos, ópticos - magnéticos autorizados por la administración tributaria utilizando la transferencia electrónica de fondos como medio de pago, apegándose a lo estipulado en el artículo 171 del Reglamento del Impuesto Sobre la Renta (2003).
Referente al cumplimiento de la normativa legal que regula los deberes formales en materia de Impuesto al Valor Agregado, se observa coherencia con la Ley de Impuesto al Valor Agregado (2014), señala en su artículo 51, la Administración Tributaria llevará un registro actualizado de contribuyentes y responsables del impuesto conforme a los sistemas y métodos que estime adecuados.

En referencia a la emisión de facturas y otros documentos, la empresa atiende al artículo 54 de la Ley de Impuesto al Valor Agregado (2014), que establece emitir facturas por sus ventas, por la prestación de servicios y por la demás operaciones gravadas.

En el marco del Reglamento de la Ley de Impuesto al Valor Agregado (1999), partiendo de los artículos 75 y 78 , en cuanto a los libros de compra y venta se conservan de forma ordenada y registrados cronológicamente y sin atrasos.

En cuanto, a la declaración mensual de impuesto al valor agregado siguiendo el artículo 59 del Reglamento del Impuesto al Valor Agregado (1999), se presenta la declaración jurada por las operaciones gravadas, realizadas en cada periodo de imposición.

De igual forma, se llevan los libros, registros y archivos adicionales conservados de forma ordenada, mientras no esté prescrita la obligación, así como también se realizan todos los registros contables de todas sus operaciones, incluyendo las que no son gravables con el IVA según lo estipulado en el artículo 56 de la Ley de Impuesto al Valor Agregado (2014).

Por otro lado, la empresa como agente de retención designado por la administración tributaria conforme al artículo 11 de la Ley de Impuesto al Valor Agregado (2014), cumple con entregar a los proveedores un comprobante por cada retención de impuesto practicado en coherencia con el artículo 16 de la Providencia Administrativa SNAT/0049 (2015).

Finalmente, Thronson Internacional de Venezuela, C.A. declara y paga de manera oportuna el impuesto correspondiente en el lugar, la fecha y forma y condición que establece el reglamento según el artículo 47 de la Ley de Impuesto al Valor Agregado (2014). 


\section{CONCLUSIONES:}

Una vez recolectado los datos a través del instrumento de validación, cotejado con lo fundamentado en las bases teóricas se realizó el análisis respectivo con cada unidad de análisis y objetivos específicos planteados en la investigación, se obtuvo una serie de resultados donde se llegaron a las siguientes conclusiones, las cuales corresponden a la evaluación de los deberes formales en materia de Impuesto Sobre la Renta e Impuesto al Valor Agregado en Thronson Internacional de Venezuela, C.A.

De esta manera, en lo que respecta al objetivo de evaluar el cumplimiento de la normativa legal que regula los deberes formales en materia de impuesto sobre la renta en Thronson Internacional de Venezuela, C.A., se concluye que la entidad posee el registro de información fiscal emitido por la Administración Tributaria, lo cual es exhibido en un lugar visible y se contempla la razón social, la clase 0 tipo de sociedad, fecha de inscripción ante la administración tributaria, domicilio fiscal y dirección de la sede administrativa.

En cuanto a la presentación de la declaración estimada la empresa no ha obtenido enriquecimientos netos mayores a 1500 U.T. en el año inmediatamente anterior, debido a esto no se realizó dicha declaración por presentar pérdida fiscal.

De acuerdo al objetivo orientado, se concluye también que la empresa presenta la declaración anual definitiva del ISLR con los resultados fiscales del periodo de imposición tanto de sus enriquecimientos como de sus pérdidas, declarando dentro de los tres (3) meses siguientes al cierre del ejercicio gravable por lo cual no han utilizado alguna prórroga para la presentación.

A su vez, no aplica la presentación de la declaración informativa, dado a que no informa las operaciones efectuadas en el ejercicio fiscal mediante la referente declaración y donde no se detalla la relación según cuentas de depósitos, ahorros o de cualquier otro tipo. Sin embargo, la empresa no realiza ajuste por inflación desde el año 2015 debido a una reforma legal emitida por el Gobierno Nacional en materia de ajuste inflacionario en Diciembre del año mencionado, la cual por la naturaleza de la organización se adapta a lo establecido.
Seguidamente, la empresa cumple a cabalidad el deber formal respecto a los libros de contabilidad con los adecuados registros, de llevarlos de forma ordenada de acuerdo a lo principios generalmente aceptados. De igual manera, los comprobantes de retención son emitidos por la organización, en los tiempos y formas correctas establecidas, demostrando así al trabajador el monto abonado o retenido.

Del mismo modo, se evidenció el cumplimiento de la declaración y pago del impuesto sobre la renta, todo bajo las normas imperativas que establece el reglamento de la ley, según los lapsos pertinentes y las formas indicadas.

Posteriormente, en referencia al objetivo que persigue evaluar el cumplimiento de la normativa legal que regula el impuesto al valor agregado en Thronson Internacional de Venezuela, C.A., se concluyó que la empresa efectivamente se encuentra inscrita ante la Administración Tributaria. Así mismo, la empresa exhibe el comprobante de inscripción en un lugar visible fiscal.

Consecuentemente, la empresa cumple con la obligación de emitir facturas y documentos por las ventas realizadas y por las demás operaciones gravadas, además de emitirlas por duplicado. Por otra parte, las facturas se presentan con la numeración consecutiva, así como la especificación del monto del impuesto según la alícuota y todos sus requerimientos. De igual forma, Thronson Internacional de Venezuela C.A., contiene los libros de compras y ventas correspondientes, además de que se encuentran los registros en orden cronológicos según las operaciones que se han realizado.

Continuando con el objetivo, se encuentra la declaración mensual del I.V.A donde la empresa paga el impuesto correspondiente en el lugar fecha, forma y condición que establezca el reglamento. Así mismo, dicha declaración es presentada dentro de los quince (15) días continuos siguientes al periodo de imposición.

Así mismo en cuanto a los registros contables, la empresa registra contablemente todas sus operaciones, incluyendo las que no son gravables con el I.V.A, además registra las nuevas facturas 0 documentos equivalentes. Del mismo modo, se observa que llevan al día los libros, registros y archivos adicionales necesarios tales como libro diario fiscal, 
libro mayor fiscal, balance general fiscal, conservando en forma ordenada mientras no esté prescrita la obligación las facturas utilizadas para la elaboración de dichos libros.

Seguidamente, al emitir los comprobantes de retención en la empresa la misma presenta un oficio designado y calificado responsable del pago del impuesto emitido por la administración tributaria, de igual forma cumple con entregar a los proveedores los comprobantes por cada retención de IVA que se les practiquen, detallando en estos la razón social del agente de retención, la fecha de emisión y el importe calculado.

Por último, señala que la organización cumple con la obligación de declarar y pagar el impuesto al valor agregado según fecha, forma y condición establecida por reglamento, cancelando el impuesto por las importaciones definitivas, así como también declara y paga los anticipos de IVA generados inmediatamente de la declaración de IVA.

En tal sentido ante las conclusiones antes mencionadas, la entidad cumple a cabalidad con lo establecido en las diferentes normas. Sin embargo, se hace necesario mantener la supervisión del cumplimiento de los deberes formales por parte del personal involucrado, en lo que se refiere a la materia de impuesto sobre la renta e impuesto al valor agregado, para así evitar posibles sanciones, logrando fortalecer el área tributaria ante una fiscalización.

\section{REFERENCIAS:}

Arias, G. (2012). El Proyecto de Investigación, Introducción a la Metodología Científica. Caracas, Venezuela. Editorial Episteme C.A.

Berrio, B. J. D. Á., Pérez, H., \& Brito, R. R. V. (2017). Gestión financiera y competitividad de las empresas prestadoras de servicios turísticos en la frontera colombo-Venezolana. FACE: Revista de la Facultad de Ciencias Económicas y Empresariales, 16(2), 38-53.

http://revistas.unipamplona.edu.co/ojs_viceinves/in dex.php/FACE/article/view/2289
Beltran, J., \& González, L. (2017). Tendencia de Investigación contable en Colombia: Teoría 0 Práctica, una mirada desde las revistas contables colombianas 2011 a 2015. FACE: Revista de la Facultad de Ciencias Económicas y Empresariales, 17(2), 68-80.

http://revistas.unipamplona.edu.co/ojs_viceinves/inde x.php/FACE/article/view/2228

Caballenas, G. (2004). Diccionario Jurídico Elemental. Buenos Aires, Argentina. Editorial Heliasta.

Código Orgánico Tributario. (2014) Gaceta Oficial Extraordinaria de la República Bolivariana de Venezuela. № 6152, Noviembre 18, 2014.

Decreto No 1.808 Retenciones de Impuesto Sobre la Renta. (1997). Gaceta Oficial de la República Bolivariana de Venezuela. No 36.203, Mayo 12, 1997.

Garay, J. (2010). Ley de Impuesto al Valor Agregado. Caracas, Venezuela. Ediciones AGR.

Garay J. y Garay M. (2012). Ley de Impuesto Sobre la Renta. Caracas, Venezuela. Ediciones AGR.

Glosario de términos Tributario SENIAT. (2015). Página web en línea disponible: http.//www.seniat.gob.ve. (Consulta: 2018, octubre).

Hernández R. Fernández C. y Baptista P. (2014). Metodología de la investigación. México DF. Editorial McGraw-Hill

Landwell. (2010). Los Procedimientos de Aplicación de los Tributos en el Ámbito Interno y en el de la fiscalidad internacional. Valladolid, España. Lex Nova S.A.

Ley de Impuesto Sobre La Renta. (2015). Gaceta Oficial Extraordinaria de la República Bolivariana de Venezuela. № 6.210, Diciembre 30, 2015.

Ley Impuesto al Valor Agregado. (2014). Gaceta Oficial Extraordinaria de la República Bolivariana de Venezuela. № 6.152, Noviembre 18, 2014.

Moncada, L. (2016). Cumplimiento de obligaciones 
tributarias en el libro de compras en Plumrose CA. Conocimiento Global, 1(1), 14-36. Recuperado a partir de http://conocimientoglobal.org/revista/index.php/cgl obal/article/view/21

Moya, E. (2012). Elementos de Finanzas Públicas y Derecho Tributario. Caracas, Venezuela. Editorial Mobilibros.

Organización para la Cooperación y el Desarrollo Económico (OCDE). (2010). Fomentando la Cultura Tributaria, el cumplimiento fiscal y la ciudadanía. Página web en línea disponible: https://www.oecd-library.org/taxation/fomentandola-cultura-tributaria-el-cumplimiento-fiscal-y-laciudadania_9789264222786-es.

Pájaro, A., \& Ramos G. (2015). Determinantes macroeconómicos del comportamiento de índice general de la Bolsa de Valores de Colombia. Aglala, 6(1), 199-228.Recuperado de: http://revistas.curnvirtual.edu.co/index.php/aglala/a rticle/view/727

Palella S. y Martins F. (2017). Metodología de la Investigación Cuantitativa. Caracas, Venezuela. Editorial Fedeupel.

Providencia Administrativa No SNAT/2015/0049. (2015). Gaceta Oficial de la República Bolivariana de Venezuela. № 40.720, Agosto 10, 2015.

Reglamento de la Ley de Impuesto Sobre la Renta. (2003). Gaceta Oficial Extraordinaria de la República Bolivariana de Venezuela. № 5.662.

Reglamento de la Ley de Impuesto Sobre la Renta. (2003). Gaceta Oficial Extraordinaria de la República Bolivariana de Venezuela. № 5.662.

Reglamento General Ley del Impuesto Al Valor Agregado. (1999). Gaceta Oficial Extraordinaria de la República Bolivariana de Venezuela. № 5.363, Julio 12, 1999.

Reglamento General Ley del Impuesto Al Valor Agregado. (1999). Gaceta Oficial Extraordinaria de la República Bolivariana de Venezuela. № 5.363, Julio 12, 1999.
Ruiz, J. (2011). Impuesto Sobre la Renta. Caracas, Venezuela. Editorial LEGIS.

Tamayo y Tamayo M. (2017). El Proceso de la Investigación Científica. Ciudad de México, México. Editorial Limusa. 